\title{
Innovation in International Business
}

\author{
Prof.as.dr.Sonela Stillo \\ Faculty of Economy, University "Fan S.Noli", Korce, Albania \\ PhD.Cand. Gentisa Furxhi \\ Faculty of Economy, University "Fan S.Noli", Korce, Albania \\ Doc.Dr. Marinela Teneqexhi \\ Faculty of Economy, University "Fan S.Noli", Korce, Albania
}

\begin{abstract}
Nowadays, international business has a relevant role in the global economy. This is due to the connection that international business has with globalization. Also, innovation has a key role in the development of international business. Innovation is considered like the basic dynamic of today economy development. The role of innovation can be evaluated, by other stakeholders who operate in the same market, as an important factor of increasing the company's value. A country that is interested to has his own innovation in order to develop his national economy, has to establish research and development centres, research institutes, universities, etc. Globalization development is associated with the development of basic rights for the protection and the development of "global products'. Different countries vary in the extent to which they protect intellectual property and enforce intellectual property regulations. The presence of strong, enforceable, consistent property rights serves to make the world flatter. However, as long as significant differences in property rights exist around the globe, the world will be far from flat with respect to innovation. In this paper, we will focus in intellectual property. We will explain what the intellectual property is, and what are the types of intellectual property. Further, we will see the differences in legislation that different countries have in the protection of intellectual property. At the end of this paper we will focus at the innovation of the business in Europe and in Albania.
\end{abstract}

Keywords: international business, globalization, intellectual property.

\section{Introduction}

\section{The importance of research and development in International Business.}

Communications and other technologies are flattening the world in regard to innovation, enabling innovation activities to be located anywhere, while the absence of legal property rights protections in some areas work against this flattener. The function of international R\&D is to increase the speed and effectiveness with which a firm can innovate. Innovation is considered as the basic dynamic of today economy development. Nowadays, innovations can be considered as one of production factors against the other factors such as workforce, capital( equity), etc. The role of innovation can be evaluated, by other stakeholders who operate in the same market, as an important factor of increasing the company's value.

Today, companies labelled as 'global companies' would not survive for a long if they do not have the R \& D department, which enable them to invent new products or services. Although, the high cost that the $R \& D$ department has, it is a necessity of time. 
The most important companies are those who produce wisdom or create new value. These are companies that in the most of time invest in the research and the development of new products. These companies invest $5 \%$ to $20 \%$ of their budget for R\&D.

At the beginning governments have played a large role in the inception of R\&D, mainly to fund research for military applications for war efforts. Today, governments still play a big role in innovation because of their ability to fund R\&D. A government can fund R\&D directly, by offering grants to universities and research centres or by offering contracts to corporations for performing research in a specific area. Governments can also provide tax incentives for companies that invest in R\&D. Countries vary in the tax incentives that they give to corporations that invest in R\&D. By giving corporations a tax credit when they invest in R\&D, governments encourage corporations to invest in R\&D in their countries. Finally, governments can promote innovation through investments in infrastructure that will support new technology.

\section{Intellectual property and intellectual property types.}

Companies, that increase investment in research to gain financial profit through innovations, must have legal protection for these inventions. The system of law related to R\&D and innovation is referred to as intellectual property rights. Different countries vary in the extent to which they protect intellectual property and enforce intellectual property regulations.

Intellectual property refers to creations of the mind-inventions, literary and

artistic works, and symbols, names, and images used in commerce. The term property connotes ownership that's exclusive, but the owners have the right to license or sell their IP. Under intellectual property law, owners are granted certain exclusive rights to the discoveries, inventions, words, phrases, symbols, and designs they create.

A patent is an exclusive right granted for an invention, whether a product or a process, which must be industrially applicable (useful), be new (novel) and exhibit a sufficient "inventive step" (be nonobvious). A patent provides protection for the invention to the owner of the patent. The protection is granted for a limited period, generally twenty years from the filing date.

A trademark is a distinctive sign, which identifies certain goods or services as those produced or provided by a specific person or enterprise. The system helps consumers identify and purchase a product or service because its nature and quality, indicated by its unique trademark, meets their needs.

A trademark is a distinctive sign that identifies certain goods or services as those produced or provided by a specific person or enterprise. A trademark uniquely identifies the source of the product. The system helps consumers identify and purchase a product or service because its nature and quality, indicated by its unique trademark, meets their needs.

Trade Secrets, any confidential business information which provides an enterprise with a competitive edge can qualify as a trade secret. A trade secret may relate to technical matters, such as the composition or design of a product, a method of manufacture or the know-how necessary to perform a particular operation. Common items that are protected as trade secrets in clude manufacturing processes, market research results, consumer profiles, lists of suppliers and clients, price lists, financial information, business plans, business strategies, advertising strategies, marketing plans, sales plans and methods, distribution methods, designs, drawings, architectural plans, blueprints and maps, etc.

A copyright is the body of laws which grants authors, artists and other creators protection for their literary and artistic creations, which are generally referred to as "works." A closely associated field of rights related to copyright is "related rights", which provides rights similar or identical to those of copyright, although sometimes more limited and of shorter duration. 


\subsection{Intellectual Rights protection}

The US government's Office of the United States Trade Representative (USTR) monitors intellectual property rights around the world and fights IP theft because IP theft impacts the 18 million Americans whose livelihood depends on IP protection. The USTR evaluates countries and rates them according to how those countries enforce IP rights. Report is an annual review of the global state of IPR protection and enforcement issued by the USTR. The worst offenders are put on a "Priority Watch List." The countries on the 2010 Priority Watch list are China, Russia, Algeria, Argentina, Canada, Chile, India, Indonesia, Pakistan, Thailand, and Venezuela. China, which has been on the Watch List before, continues to be on the list not only because of IP theft and counterfeiting but also because of government practices that severely

restrict the market for foreign goods while giving favored treatment to "indigenous innovation. The Czech Republic, Hungary, and Poland were all removed from the Watch List because they took significant steps to clamp down on piracy and counterfeiting.

The World Intellectual Property Organization (WIPO) is a specialized agency of the United Nations that works to harmonize the intellectual property laws of countries around the world. Although the roots of the WIPO go back to 1883, WIPO became an agency of the United Nations in 1974, with a mandate to administer intellectual property matters recognized by the member states of the UN. In 1996, WIPO expanded its role and further demonstrated the importance of intellectual property rights in the management of globalized trade by entering into a cooperation agreement with the World Trade Organization (WTO). Today, WIPO seeks to harmonize national intellectual property legislation and procedures, to provide services for international applications for industrial property rights, to exchange intellectual property information, to provide legal and technical assistance to developing and other countries and to facilitate the resolution of private intellectual property disputes.

\subsection{The protection of intellectual property in Albania}

The main institutions responsible for administering and monitoring the rights of industrial and intellectual property in Albania are:

General Directory of Licenses and Brands- the mission of this institution is to strengthen the protection of industrial property inside the Albania territory through the recognition and/or registration of these rights and through the creation of conduct sheets of applicable rights and laws in Albania. Since 2009, the General Directory of Licenses and Brands uses database system for industrial property. IPAS (Industrial Property Automated System), installed from WIPO in 2006, is used in order to register the international applications for the registration of brands in an electronic way according to the Treaty of Madrid and the Protocol Of Madrid. The implementation of IPAS has accelerated the processing of applications and has improved the accuracy of the data in connection with the subjects of industrial property, and this is important for the processes developed before the General Directory of Licenses and Brands, the public in general and the implementation of industrial property rights in particular. It also provides an electronic circulation of data in support of the publication of the Bulletin in an electronic version in the webpage of the General Directory of Licenses and Brands.

- Albanian Office of Copyright- it is a central institution, a legal and public person, assigned by the Ministry of Tourism, Culture, Youth and Sports to fulfill the obligations of Albania in the field of copyright. This office is created as a result of the immediate need to fight piracy and the violation of intellectual property that exists in Albania. The duties of the office are focused on:

- $\quad$ Raising the awareness of public into the general matters of copyright and other rights connected to it, in collaboration with a number of organs of the central government.

- The monitoring of the protection of copyright and other rights connected to it.

- The creation of an appropriate system of collective administration of copyright.

The General Directory of Licenses and Brands and The Albanian Office of Copyright are the main responsible institutions, engaged directly with the matters of industrial property, intellectual property and copyright in Albania. They collaborate with 
a number of other institutions, which support their work. These institutions are: General Directory of State Police and General Directory of Customs.

General Directory of State Police. The structure inside this directory, responsible for the cases of copyright, is The Directory Against Financial Crime, which deals penal acts in the economic sector, regulated by the Penal Code. Practically, the directory faces a lot of difficulties regarding copyright in Albania. Unfortunately, the Albanian market is filled with forged goods, mainly imported and only a small part produced in Albania. Legislation may be considered as a major problem regarding the treatment of forged goods and brands. Currently, the Penal Code does not provide any appropriate measure which can be taken for these actions. Until now, the police have been trying to react based on act 109 "Falsification of seals, stamps and forms" and act 288 "lllegal production of industrial and food products", but none of the mentioned provisions can be used in the case of forged products. The reason is that act 109 is usually not applied and act 288 is only applied if production happens. This is the reason why no measure against the violator can be taken and this violator can't be punished or imprisoned, because in most of the cases forged goods and brands are not produced in Albania and no factory of production is found in the country. However, the involved institutions have proposed concrete changes of the Penal Code(act 147,148,149 are in particular dedicated to falsification and fraud in works of art, culture, publication of somebody else's work under your name, production of a work without the authorization of authors.) and the Code of Penal Procedure(act 59 and 284). The changes are part of the legislative framework of Ministry of Justice for 2010. The changes must help the police to efficiently protect the rights of intellectual property in Albania.

General Directory of Customs. Albania Customs Administration has a legal obligation to control all products, means of transport and the passengers that pass the border in any territory under the sovereignty of the Albanian state. Currently, through this directory, customs authorities have the right to:

- $\quad$ React based on the formal request of the owner of the copyright

- React based on ex officio

- $\quad$ Block the products

- Take temporary measures in the cases when the owner of the copyright ia able to prove the violation of intellectual property rights

- $\quad$ Destroy pirated and forged products

The two mentioned institutions, regarding the object of their work, have a weak connection with the subject of the General Directory of Licenses and Brands. As a matter of fact, functional schemes of the Sector of Fight against Economic Crime and the Directory of Intellectual Property Defense do not have an integrating structure with the functional processes of the General Directory of Licenses and Brands and the Albanian Office of Copyright.

\section{Innovation in the businesses in Europe}

A dynamic business environment is essential in promoting and spreading innovation. The real challenge is about using the research and development $(R \& D)$ through ventures and creativity to encourage innovation and economical competition. Therefore, the measures that aim the spreading of knowledge and absorption of ideas and innovations, for example, through the creation of technological markets and licensing schemes, are as important as the investments in knowledge.

Almost half of the enterprises in EU contribute in the activity of innovation. (Fig.3.1)

The intellectual ownership is mostly developed in the European region, because of the fact that a lot of European businesses have created their brands. The creation of different brands has brought the innovation in the international business. European companies have applied for international patents because they require protection for all the ideas, products or services that they have launched and developed. The European companies have developed many brands, which helps in developing the rights of the intellectual ownership. Another innovation that had an impact in the development of the European businesses is the creation of departments of research and development. They have played the main role in the development and success of the European companies, thing that is witnessed by the statistical data (Fig.3.2). 
It is noticed that from year to year there is an increase in applications for trend and brand protection. In 1997 there was a decrease of the applications and in 1998 there was a gradual increase. There was also a fluctuation during the years $2000-$ 2003, but then it was followed by a continuous increase after 2004 .

\subsection{The European investments in the Research-development department}

The indicator called "gross domestic expenses in the department of research-development" indicates the percentage of the gross domestic production (GDP) dedicated to the research and development. It is referred as the "intensity of researchdevelopment" and it mirrors the degree of research and innovation undertaken in a country in the aspect of resource contribution.

The data in the following tables show a prolonged stagnation of the internal gross expenses in research and development $(R \& D)$ in about $1.81 \%$ of the gross domestic product (GDP) for the period 2002-2007. From 2009, in the start of the economical crisis, R \& D was increased in 1.94\%. From 2011 it has continued with a small increase, with a stability in $2,03 \%$ in 2013 and 2014. One of the reasons for the increase in the middle of 2007 and in 2009 is the decrease of the GDP faster than the general expenses of research-development R \& D (see the Report of Competition Union Innovation 2011). Between 2007 and 2009 , GDP fell by $5.1 \%$ in EU-28, while the R \& D expenses decreased with only $3.4 \%$. The actions taken by the individual member states to increase the investments in $R \& D$ during the low increase of the GDP helped in increasing the intensity of $R \& D$ in that period. In 2009, many member states had a nominal increase in the expenses of research and development to object the impact of crisis in the private investments (see the Report of Competition Union Innovation 2013). Although the increase of public and private research and the expenses for development in the period 2007-2014, EU moved in its accomplishment 3\% of the objective. The evaluations show that for 2020, R \& D must be accomplished; the annual rate of growth of R\&D of the EU must be increased more than three times comparing to 20072014 (the period $-6.7 \%$ vs 1.9\%), (see Science, research and innovation Performance of EU). In global level, EU is still behind other players, as the United States, Japan and South Korea. (Fig.3.3)

The following table shows the leaders of innovation in Europe (Fig.3.4)

\section{Innovation in businesses in Albania}

The Albanian government was maximally engaged in reforms that aim the creation of a proper environment of fair competition. In July 2016, the Council of Ministers approved "the National Strategy for the Intellectual Ownership", 20162020. This strategy is an intersectional document that crowns one of the efforts of the government in establishing a comprehensive dialogue between different actors, to create suitable conditions for respecting and protecting the intellectual ownership.

In a specific way, the strategy aims the promotion of the Albanian economy towards an innovative economy based in knowledge. A part of this strategy is ensuring the rights of the Intellectual Property, the proper function of the justice system, as well as the modernization of the institutions involved in the system.

\subsection{The increase of applications for the products and services of the intellectual ownership in the last three years}

From the statistical data, the number of the object registrations of $\mathrm{PI}$ that come from the membership in conventions and agreements over the Industrial Ownership, are increasing in the last years. This shows that the Albanian territory is becoming more and more attractive for the foreign companies who show interest for expanding the protection through registration in Albania. If we refer to the statistics, about $97.5 \%$ of all registered patents in DPPM are patents issued by the Office of European Patents (OEP) and have expanded or have become valuable in Albania.

In the list of 20 first places that had the right for patenting in Albania during the period 1997-2015, are multinational pharmaceutical and chemical foreign companies. These companies own about $40 \%$ of the patents registered in the republic of Albania. It is important that in the period 2013-2016 the number of applications for patents from Albanian inventors has 
risen year after year. An increase is seen also in the applications from the international agreements about the patents, concretely $25 \%$ comparing to $2015,59.8 \%$ comparing to 2014 and $90 \%$ comparing to 2013 .

The following table (Tab.4.1) shows the number of applications and the total of the patents from Albanian citizens, European patents and the patents from the treaty of cooperation about the patents.

For the applications for the protection of the brands in Albania we can say that in the year 2015, DPPM accepted 3492 brand applications, having a considerable increase compared to the year 2014, when there were only 3319 applications accepted and 3282 applications accepted in 2013. There was an increase in the number of the Albanian applications that till November 2016 it was 561 compared to 509 applications in 2015, 421 in 2014 and 376 applications in 2013. From the agreement and the Madrid Protocol till November 2016 have been deposited 2124 applications, 2555 applications in 2015, compared to the year 2014 when were deposited 2414 applications and 2507 in 2013.

In the increase of the number of the national applications the most impactful factors were the economical growth, the increasing of the number of the registered new local businesses, the empowering of those existent, the increase in the range of the products that they produce and also the work of the employees of DPPM in spreading the awareness among the businesses about the importance of the registration of their brands. From the number of applications from foreign owners, we notice that in total there is an increase in the number of the foreign applications from 2898 in 2014, in 2984 in 2015, so 86 more applications than in 2015. This is because many people who make business for the first time in different countries have found it more reasonable the international way of application for registration, because the Agreement and the Madrid Protocol provides more facilities; from the application method (through the application in many countries at the same time), to cheaper fee, using only one foreign language eliminating the need for more authorized representatives.

The following table (Tab.4.2) shows the number of the requests from Albanian applicants, the number of the requests from foreign applicants and the number of requests for registration in the Agreement and the Madrid Protocol in the last 3 years.

There are three ways for registering patents in Albania:

- Applications for patents that appear directly in the DPPM as a national application;

- Applications for patents through the Treaty of Collaboration for the Patents (TCP);

- Patents issued from the European Office of the Patents (EOP) and that require extension of protection in Albania.

Almost all the patents valid in Albania are patents granted in EOP and have effect in Albania according to the EOP agreement or according to the European Convention about the Patents (ECP).

About $97.5 \%$ of all patents registered in DPPM are patents issued by the Office of European Patents (OEP) and are extended or made valid in Albania. This means that almost all the patents in power in Albania are given by the OEP and are part of a big family of patents that are protected even in other countries members of ECP.

From 1997 to 2015, have only been 68 applications for patents by Albanian applicants directly in DPPM, which is $1.16 \%$ of the total applications.

The applications from the universities and research institutions represent a little more than $2 \%$ of the applications for patents in DPPM. The low number of applications for patents from the universities has been constant the whole time. Universities and research institutes which apply for the protection of patents in Albania, are mainly located in the countries of EU and USA and their applications are mainly focused in applications for pharmaceutical and chemical patents.

Most of the foreign companies, which have their patents protected in Albania, do not have their brands registered.

\section{Conclusions}

- The function of international R\&D is to increase the speed and effectiveness with which a firm can innovate. 
- Innovation is considered as the basic dynamic of today economy development.

- Today, companies labelled as 'global companies' would not survive for a long if they do not have the R \& D department, which enable them to invent new products or services.

- Governments play a big role in innovation because of their ability to fund R\&D.

- Governments can promote innovation through investments in infrastructure that will support new technology.

- The system of law related to R\&D and innovation is referred to as intellectual property rights.

- Intellectual property refers to creations of the mind-inventions, literary and

o artistic works, and symbols, names, and images used in commerce.

- Types of intellectual property are: patents, trademarks, trade secrets and copyrights.

- The US government's Office of the United States Trade Representative (USTR) monitors intellectual property rights around the world and fights IP theft.

- The World Intellectual Property Organization (WIPO) is a specialized agency of the United Nations that works to harmonize the intellectual property laws of countries around the world.

- The main institutions in Albania responsible for administering and monitoring industrial and intellectual property are: General Directorate of Patents and Trademarks, Albanian Office for Copyrights, General Directorate of State Police and General Directorate of Customs.

- Intellectual Property is very developed in Europe, this is due to the fact that many European businesses have created their brands and they have developed their R\&D departments.

- Albanian government is very committed to reforms aimed at creating an enabling environment for fair competition.

- In July 2016, the Council of Ministers adopted the "National Strategy for Intellectual Property", 2016-2020.

- For the period 2013-2016 the number of patent applications from Albanian inventors has noticeably increased year after year.

- Also, applications from international agreements on patents have significantly increased, namely $25 \%$ compared to 2015 , compared with $59.8 \%$ in 2014 and $90 \%$ compared with 2013 .

- Also, there is an increase in the number of foreign applications from 2898 to 2014,2984 to 2015 , then 86 more applications in 2015.

\section{References}

[1] Annual Report of General Directory of Patents and Trademarks, Albania 2016

[2] Intellectual Property Law; Tanya Frances Aplin, Tanya Aplin, Jennifer Davis; 2013

[3] Challenges and Opportunities in International Business (v. 1.0); Manson A. Carpenter; Sanjyot P. Dunung; 2012

[4] Patent it Yourself; Davis Pressman; 18 edittion; 2012

[5] http://www.academia.edu/4037273/E_drejta_e_Autorit_ne_BE

[6] http://www.wipo.int/multimedia-video/en/ipstats/ëipi_2016_highlights.mp4

[7] http://www.wipo.int/edocs/pubdocs/en/ëipo_pub_941_2016.pdf

[8] http://www.balkanweb.com/gazetashqiptare/shqiperia-sfidat-e-reja-per-pronesine-intelektuale/

[9] http://www.dogana.gov.al/sites/default/files/STRATEGJIA_IPR_DPD.pdf

[10] https://www.ata.gov.al//ako-per-atsh-ne-pronesia-industriale-motorr-nxites-i-zhvillimeve-te-tregut

[11] http://www.innovationmanagement.se/2010/12/08/convoy-model-the-dynamic-perspective-of-porters-clustermodel.

\begin{tabular}{|l|l|l|l|l|}
\hline & $\begin{array}{l}\text { Applications for } \\
\text { international patents }\end{array}$ & EP & PCT & TOTAL \\
\hline 2013 & 4 & 340 & 4 & 348 \\
\hline 2014 & 12 & 409 & 2 & 423 \\
\hline 2015 & 17 & 520 & 2 & 539 \\
\hline November 2016 & 24 & 655 & 2 & 681 \\
\hline Total & 57 & 1924 & 10 & 1991 \\
\hline
\end{tabular}


Tab. 4.2: The number of applicants for the registration from the Agreement and the Madrid Protocol during the last 4 years.

Source: The annual report (2016) The General Directory of Patents and Brands

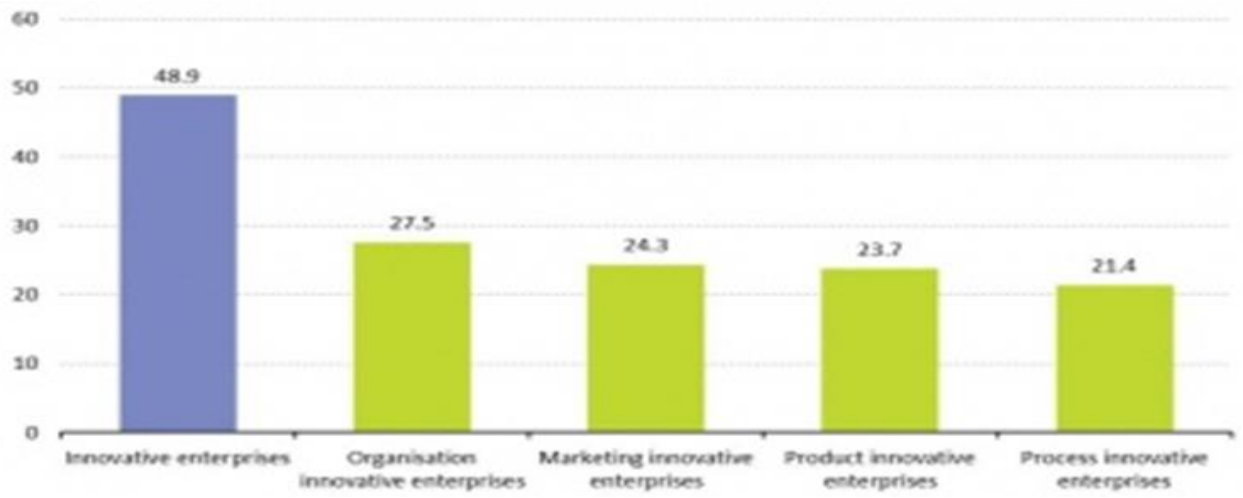

Fig 3.1: Enterprises according to the type of innovation, Source: Eurostat 2012

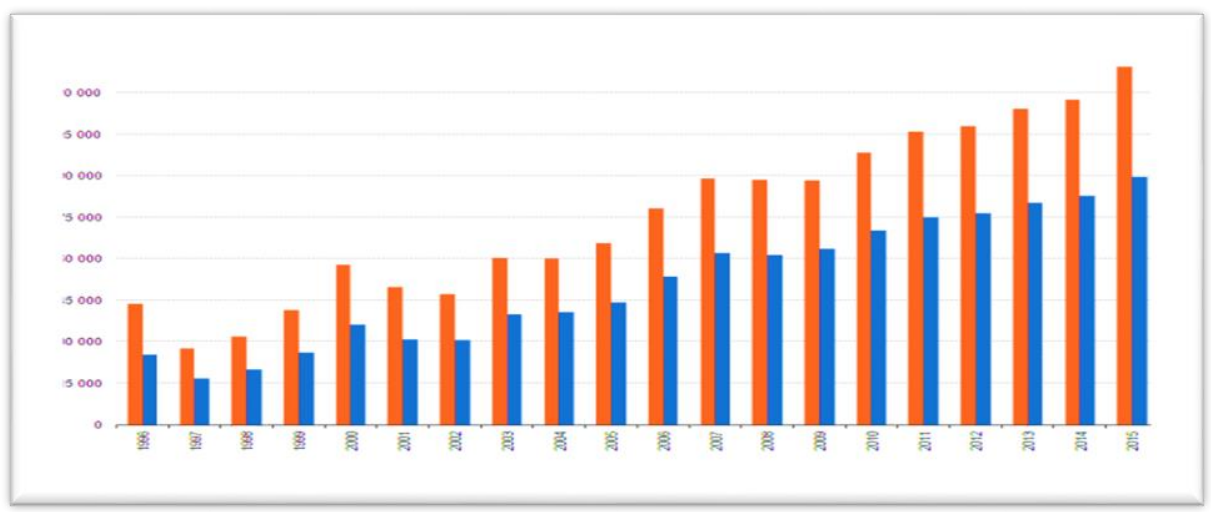

Fig. 3.2: The number of applications for brand and patent protection in Europe and in the world.

\section{Source: WIDO 2015}

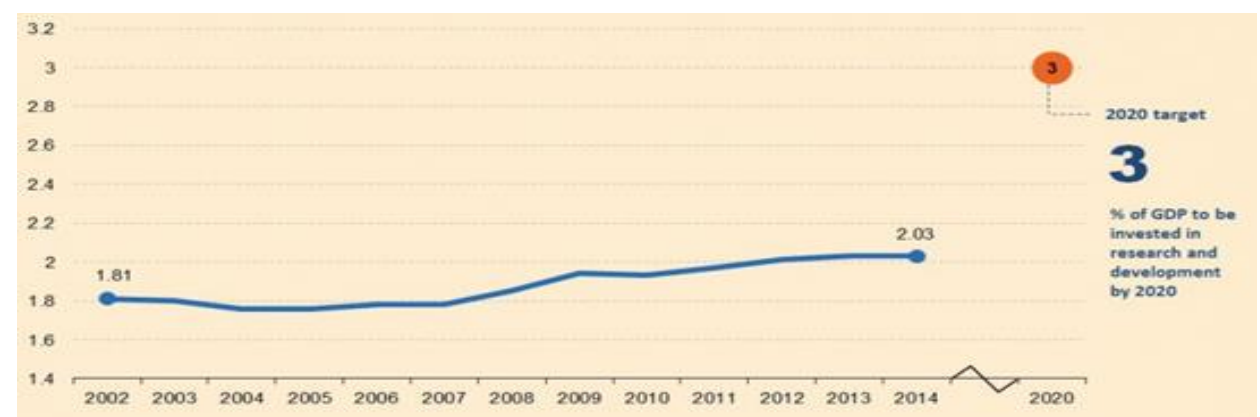


Fig.3.3: The Gross domestic expenses in R\&D, Source: Eurostat 2015

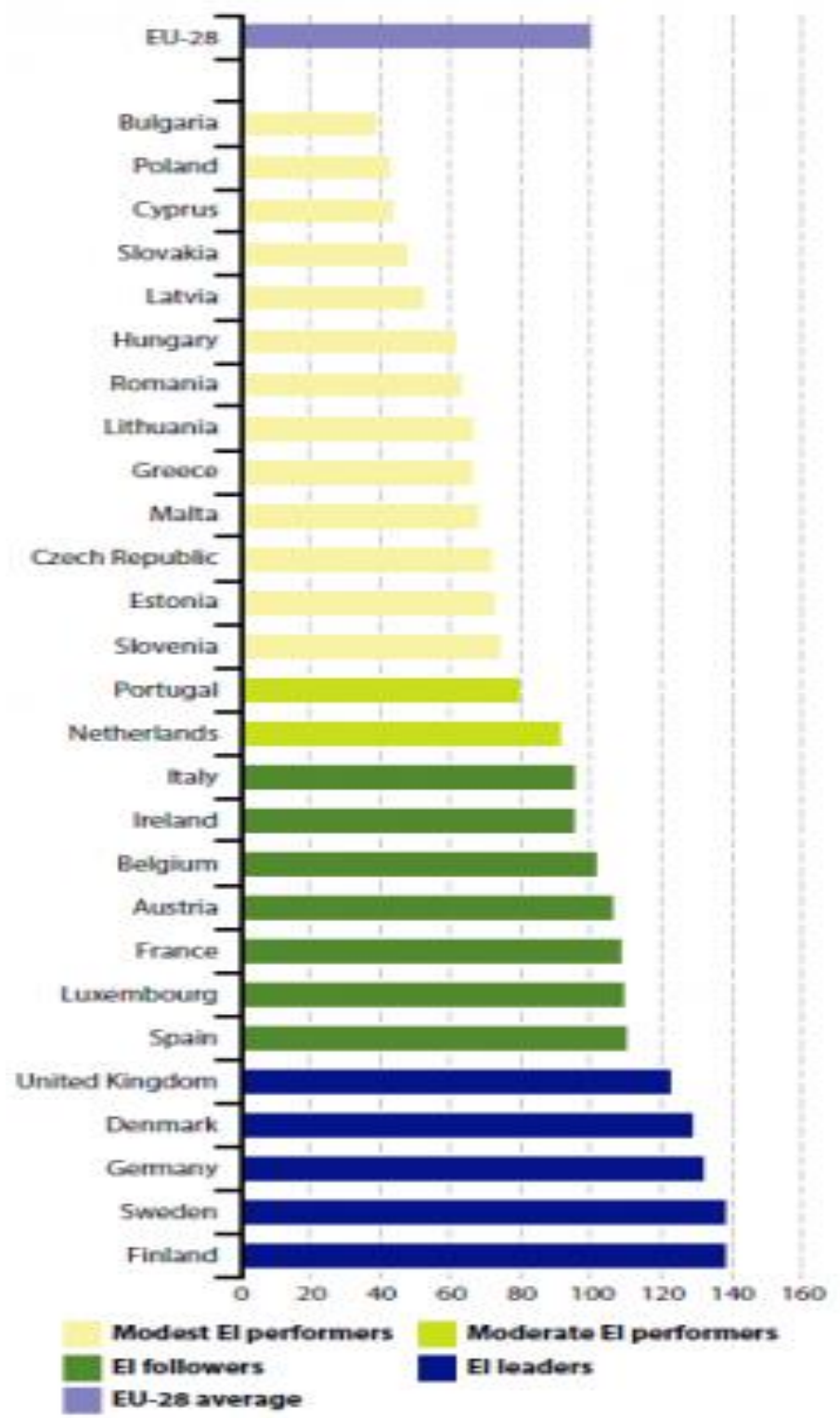

Fig.3.4: The leaders of innovation in Europe,

Source: Eurostat 2015 